Fixed Point Theory, 21(2020), No. 1, 181-190

DOI: $10.24193 /$ fpt-ro.2020.1.13

http://www.math.ubbcluj.ro/ nodeacj/sfptcj.html

\title{
EXISTENCE RESULTS FOR A QUADRATIC INTEGRAL EQUATION OF FRACTIONAL ORDER BY A CERTAIN FUNCTION
}

\author{
H.H.G. HASHEM* AND A.M.A. EL-SAYED** \\ *Department of Mathematics, College of Science, Qassim University, \\ P.O. Box 6644 Buraidah 51452, \\ E-mail: 3922@qu.edu.sa, hendhghashem@yahoo.com \\ **Faculty of Science, Alexandria University, Alexandria, Egypt \\ E-mail: amasayed@alexu.edu.eg
}

\begin{abstract}
The fractional integration of a function $f(t)$ by a function $\phi$ and some of its properties is presented in [23], [30] and [21]. As an application for this fractional integration we present some existence results for at least one continuous solution for a nonlinear quadratic functional integral equation of fractional (arbitrary) order. Also, some examples and remarks are illustrated. Finally, we prove the existence of maximal and minimal solutions for that equations.

Key Words and Phrases: Quadratic integral equation, Schauder fixed point theorem, continuous solution, maximal and minimal solutions.
\end{abstract}

2010 Mathematics Subject Classification: 32A55, 11D09, 47H10.

Acknowledgment. The authors are thankful to the referee for the time taken to review this paper and for the remarks that helped improve the quality of the paper.

\section{REFERENCES}

[1] I.K. Argyros, Quadratic equations and applications to Chandrasekhar's and related equations, Bull. Austral. Math. Soc., 32(1985), 275-292.

[2] I.K. Argyros, On a class of quadratic integral equations with perturbations, Funct. Approx., 20(1992), 51-63.

[3] J. Banaś, J. Caballero, J. Rocha, K. Sadarangani, Monotonic solutions of a class of quadratic integral equations of Volterra type, Comput. Math. Appl., 49(2005), 943-952.

[4] J. Banaś, M. Lecko, W.G. El-Sayed, Existence theorems of some quadratic integral equation, J. Math. Anal. Appl., 227(1998), 276-285.

[5] J. Banaś, A. Martinon, Monotonic solutions of a quadratic integral equation of Volterra type, Comput. Math. Appl., 47(2004), 271-279.

[6] J. Banaś, J. Rocha Martin, K. Sadarangani, On the solution of a quadratic integral equation of Hammerstein type, Math. Computer Model., 43(2006), 97-104.

[7] J. Banaś, B. Rzepka, Monotonic solutions of a quadratic integral equations of fractional order, J. Math. Anal. Appl., 332(2007), 1370-11378.

[8] J. Banaś, B. Rzepka, Nondecreasing solutions of a quadratic singular Volterra integral equation, Math. Comput. Modelling, 49(2009), 488-496. 
[9] M. Cichon, M.A. Metwali, On quadratic integral equations in Orlicz spaces, J. Math. Anal. Appl., 387(2012), no. 1, 419-432.

[10] R.F. Curtain, A.J. Pritchard, Functional Analysis in Modern Applied Mathematics, Academic Press, 1977.

[11] K. Deimling, Nonlinear Functional Analysis, Springer-Verlag, Berlin, 1985.

[12] M.M. El-Borai, W.G. El-Sayed, M.I. Abbas, Monotonic solutions of a class of quadratic singular integral equations of Volterra type, Int. J. Contemp. Math. Sci., 2(2007), no. 2, 89-102.

[13] A.M.A. El-Sayed, F.M. Gaafar, H.H.G. Hashem, On the maximal and minimal solutions of arbitrary-orders nonlinear functional integral and differenbtial equations, Math. Sci, Res. J., 8(11)(2004), 336-348.

[14] A.M.A. El-Sayed, H.H.G. Hashem, Carathèodory type theorem for a nonlinear quadratic integral equation, Math. Sci. Res. J., 12(2008), no. 4, 71-95.

[15] A.M.A. El-Sayed, H.H.G. Hashem, Monotonic positive solution of nonlinear quadratic Hammerstein and Urysohn functional integral equations, Commentationes Math., 48(2008), no. 2, 199-207.

[16] A.M.A. El-Sayed, H.H.G. Hashem, Monotonic solutions of functional integral and differential equations of fractional order, Electronic J. Qualitative Th. Differential Eq., 7(2009), 1-8.

[17] A.M.A. El-Sayed, H.H.G. Hashem, Monotonic positive solution of a nonlinear quadratic functional integral equation, Appl. Math. and Comput., 216(2010), 2576-2580.

[18] A.M.A. El-Sayed, H.H.G. Hashem, Existence results for nonlinear quadratic functional integral equations of fractional order, Miskolc Mathematical Notes, 14(2013), no. 1, 79-87.

[19] A.M.A. El-Sayed, H.H.G. Hashem, E.A.A. Ziada, Picard and Adomian Methods for quadratic integral equation, Comput. Appl. Math., 29(2010), no. 3, 447-463.

[20] W.G. El-Sayed, B. Rzepka, Nondecreasing solutions of a quadratic integral equation of Urysohn type, Comput. Math. Appl., 51(2006), 1065-1074.

[21] H.H.G. Hashem, On the solution of a generalized fractional order integral equation and some applications, J. Fractional Calculus Appl., 6(2015), no. 1, 120-130.

[22] H.H.G. Hashem, M.S. Zaki, Carathèodory theorem for quadratic integral equations of ErdyéliKober type, J. Fractional Calculus Appl., 4(2013), no. 5, 1-8.

[23] A.A. Kilbas, H.M. Srivastava, J.J. Trujillo, Theory and Applications of Fractional Differential Equations, Elsevier, North-Holland, 2006.

[24] V. Lakshmikantham, S. Leela, Differential and Integral Inequalities, vol. 1, Academic Press, New York-London, 1969.

[25] G. Pagnini, Erdélyi-Kober fractional diffusion, Fract. Calculus and Appl. Anal., 15(2012), no. $1,117-127$.

[26] I. Podlubny, Fractional Differential equations, San Diego - New York - London, 1999.

[27] M.R. Rao, Ordinary Differential Equations, East-West Press, 1980.

[28] B. Ross, K.S. Miller, An Introduction to Fractional Calculus and Fractional Differential Equations, John Wiley, New York, 1993.

[29] H.A.H. Salem, On the quadratic integral equations and their applications, Computers and Mathematics with Applications, 62(2011), 2931-2943.

[30] S.G. Samko, A.A. Kilbas, O. Marichev, Integrals and Derivatives of Fractional Orders and Some of their Applications, Nauka i Teknika, Minsk, 1987.

Received: January 9, 2018; Accepted: May 16, 2018. 